\title{
INVESTIGATION OF THE EFFECT OF SPECIALIZED EXERCISES FOR JUMP ENDURANCE AT AEROBICS TRAINING
}

\author{
M. Ignatova*, I. Barova \\ Department Physical Education and Sports, University of National and World Economy, Sofia, \\ Bulgaria

\begin{abstract}
The current article presents the results of the effect of applied specialized exercises for improvement of the jump endurance of female students, from the UNWE at mass aerobics classes. For proving our assumption that the purposeful impact on jump endurance at aerobics classes will improve it, we carried out an experiment within one semester limit (educational year 2019/2020). In it, 40 female $1^{\text {st }}$ and $2^{\text {nd }}$ year students from all specialties performing the exercises set in the educational curriculum have participated, in a complex with added elements for improving the jump endurance. We have subjected the results got from the control measurements, to mathematical-statistical processing. The investigation carried out proved to be successful, but regardless of this, it is necessary to look for possibilities for a bigger intensity and effectiveness, all the time.
\end{abstract}

Key words: female students, aerobic complexes, intensity

\section{INTRODUCTION}

Revealing of the real condition and position of the physical exercises in everyday life of students is of great importance, as they are the most powerful means in the fight against the negative effects, disproportion between the growing intensification of educational activity, social conditions of life and decreasing of motor workout and physical capabilities of students' youth (1).

"Physical education and sports - aerobics" subject, with the UNWE is one of the preferred disciplines among students, due to its dynamic and emotional essence, realized at a direct execution of certain motor workout. The active cognitive workout is a good precondition for an effective educational activity and for realization of the end purpose - physical, motor and personality forming of the student. The aim of mass aerobics is stimulating a steady motivation for a healthy way of life, increasing the functional capabilities of cardio-

\footnotetext{
*Correspondence to: Milena Ignatova, University of National and World Economy, Department Physical Education and Sports, 1700, Sofia, Bulgaria, Studentski grad, E-mail: mignatova@unwe.bg, GSM: +359889770004
}

vascular and breathing systems, developing of physical qualities such as force and general endurance, improving flexibility, coordinating the movements. All this supposes the availability of special physical preparation too, directed to "development and perfection of these motor qualities and habits that are precondition of a successful performance of the particular exercises" (2).

M. Bachvarov, 2005, defines the jump endurance as a capability to maintain the effectiveness of jumps with different jump back - by one or two legs, consecutively or by shifting left and right leg (3). For this specific muscle work, the level of explosive force is determinant (4). Criterion for measuring the jump endurance could be the length of road, overcome for a certain number of horizontal jumps, number of jumps for overcoming a standard length of 30-100 meters, number of successful jumps at a height $30-60 \mathrm{~cm}$ by one or two legs for time. Jump endurance principally is speed-force (power) endurance and has particularly important significance, because apart from muscle endurance it develops internal-functional qualities too. That is why we have decided to follow up what the effect will be from including of exercises for 
jump endurance with students, practicing mass aerobics at the UNWE. Other colleagues of ours have carried out investigations in this direction too. According to L. Kasabova, 2019, „methods for training, combining polymetric and myometric regime of work with respective force trainings by means of weight and multijumps, gives significantly higher growth for improving the springing off, with female students from basketball groups of the UNWE“" (5).

Modernism and facilitation for the practice at the universities, is the preparation and presenting of individual assessment tables in on-line platforms, i.e. immediately after measuring, the result is entered on e-accessible table and the point result is automatically shown (6).

The theme of physical preparation and speedforce endurance is basic one in scientific papers of Ralitsa Arsova. In her monograph she considers the special force and improvement of speed-force qualities with growing up volleyball players. Using experimental programmes in fitness and field /volleyball playground/, Arsova aims increasing the effectiveness of work for the development of the special force in volleyball, the speed-force endurance included. Volleyball players perform between 130-200 jumps averagely per match (7).

In other scientific investigations of hers with the female volleyball players from the student's team of the UNWE, Ralitsa Arsova also has investigated the special force, and in the sport-pedagogical testing of female contestants, 12 indices have been included, bearing information of the level of development of the special force, both for upper and lower limbs and torso - standing long jump and after speeding up, vertical standing jump, and after speeding up squatting till refusal, holding force and etc. $(8,9)$.

The specialized sport preparation of students creates possibility through the knowledge, skills and habits gained, generating new ones too, which is a qualitative moment not only in the development of personality, but of the educational process too.

\section{METHODS}

The aim of this work is to establish the influence of the applied exercises for improvement of the jump endurance of female students from the aerobics groups, with the UNWE.

Tasks of the investigation:

1. Developing a complex of exercises for additional influence on the jump endurance.

2. Processing of the data of the carried out measurements.

3. Carrying out a comparative analysis between the beginning and end of the semester.

Methods of investigation

1. Processing and analysis of the data from scientific-methodical literature.

2. Pedagogical survey.

3. Sport-pedagogical experiment.

4. Mathematic-statistical methods

\section{Organization of investigation}

We have carried out an experiment within the range of one semester of the educational 2019/2020 year. The experiment has put the aim to prove our supposition, that applying a complex of exercises for additional impact on the jump endurance, would improve the same. In the development, 40 female $1^{\text {st }}$ and $2^{\text {nd }}$ year students from aerobics groups have participated. During the semester, the girls fulfilled the plan set in the approved educational curriculum and the additional exercises supplemented by us.

Testing has been carried out in the beginning and in the end of first semester, on the following indices (Table 1).

\section{Content of the model in sport-pedagogical experiment}

During the semester, the trainings have been held once a week. In each class, the female students have worked after the following model:

Preparatory part, of duration 5-10 min in which they perform basic steps and generallydeveloping exercises of low intensity.

\section{Basic part:}

Basic part - it is divided into two sub-parts: aerobic work and exercise for the separate muscle groups.

The introductive aerobic work includes a series of basic steps of low intensity and variations in a continuous combination, and the real aerobic complex characterizes with developing the maximum breathing capabilities of the trainees. In it, movements of high intensity like 
running, waves, jumps and etc., are included, followed by ,after" aerobic series, at which we observe a gradual and lightly decreasing of the pulse frequency. Exercises for the separate muscles groups are performed in the second half of the basic part. Predominantly, the impact was on the components of physical capability: force, force/jump endurance and flexibility.

Table 1. Investigated indices

\begin{tabular}{|c|c|c|c|}
\hline № & Denomination of the Test & $\begin{array}{c}\text { Measure } \\
\text { units }\end{array}$ & $\begin{array}{c}\text { Precision of } \\
\text { measurement }\end{array}$ \\
\hline 1. & Age & years & $\begin{array}{l}\text { Up to } 1 \\
\text { month }\end{array}$ \\
\hline 2. & Height & centimeters & up to $1 \mathrm{~cm}$ \\
\hline 3. & Weight & kilograms & up to $1 \mathrm{~kg}$ \\
\hline 4. & BMI (Body Mass Index) & $\mathrm{kg} / \mathrm{m}^{2}$ & $\begin{array}{c}\text { up to } 0,1 \\
\mathrm{~kg} / \mathrm{m}^{2}\end{array}$ \\
\hline 5. & Jump to semi-squat with legs apart & n/90 sec & up to $1 \mathrm{sec}$ \\
\hline 6. & Sidewise jumps & $\mathrm{n} / \mathbf{4 5 s e c}$ & up to $1 \mathrm{sec}$ \\
\hline 7. & PF beginning & b/min & up to $1 \mathrm{~b}$ \\
\hline 8. & PF end & b/min & up to $1 \mathrm{~b}$ \\
\hline 9. & PF $1^{\text {st }}$ minute & b/min & up to $1 \mathrm{~b}$ \\
\hline 10. & PF $2^{\text {nd }}$ minute & b/min & up to $1 \mathrm{~b}$ \\
\hline 11. & PF $3^{\text {rd }}$ minute & b/min & up to $1 \mathrm{~b}$ \\
\hline
\end{tabular}

During the first month from the beginning of the semester, the female students performed the educational curriculum set, including aerobic series of 20 minutes duration with intensity 120 /mus. beats per minute/, increased gradually until reaching duration of 30 minutes with intensity 130 /mus. beats per minute/ during the second semester, and at the end of the semester - the desired by us $30-35$ min aerobic work with $140 /$ mus. beats per minute /. After each series and a break of 60 sec in unison with the increasing capabilities of female students, we added a model of 5 exercises for improving the jump endurance of duration $10 \mathrm{sec}$ for each element in the beginning of the semester and gradual increasing until reaching $20 \mathrm{sec}$ for an exercise in the end, without break intervals between the separate jumps.

\section{Complex of exercises for improvement of jump endurance}

1. From standing starting position, performing vertical jumps on a step platform of $15 \mathrm{~cm}$ height, upper limbs elbow folded to the body.

2. From standing starting position serial performing of squatting with touching the floor, followed by a vertical jump, with hands waving up the level of the head.

3. From starting the main posture position, performing two vertical jumps to cross attack backwards, alternating right and left leg, arms akimbo.
4. From starting the main posture position performing two vertical jumps to straddling semi-squatting, arms akimbo.

5. From standing starting position, performing consecutive jumps by left and right leg on a step platform of height $25 \mathrm{~cm}$, upper limbs elbow folded to the body.

\section{Concluding part:}

In this part, exercises for development of flexibility at coxofemoral and shoulder joints, spinal column, stretching.

\section{RESULTS}

Data from variation analysis show that the group is highly heterogeneous on control indices No.3 (,bodyweight”), No.5 (,Jumping Jack”) and No.6 (,Side jumps") and highly homogeneous for the remaining 3 indices - age, height and BMI, supported by the extent of deviation from the standard quantity.

The spread is extremely big and marks values in the range 30-52 measure units for the respective indices (weight and both types of jumps). Differences between the minimum and maximum values of the weight are within the range $42 \mathrm{~kg}$ and $94 \mathrm{~kg}$, which quite logically leads to maximum value of BMI $(30,69)$, showing obesity. Indices for the form of distribution As и Ex also give multidirectional information. Critical values at $n=33$ for As are 0,795, and 1,556 for Ex. For four of the 6 indices, the distribution is 
symmetrical and has normal excess (age, height, and the two types of jumps).

From the results got, at bases investigation, we could make the conclusion, on condition that the investigated group is homogeneous as regards the anthropometric tests, and highly heterogeneous for the control jump exercises.
For the time of the experiment, there are no changes as regards the control indices ,age" and „height", due to which we do not include them in the graphic analysis. In Figure 1, the average values of the measured data are presented, on the separate tests in the beginning and in the end of the experiment. (Figure 1)

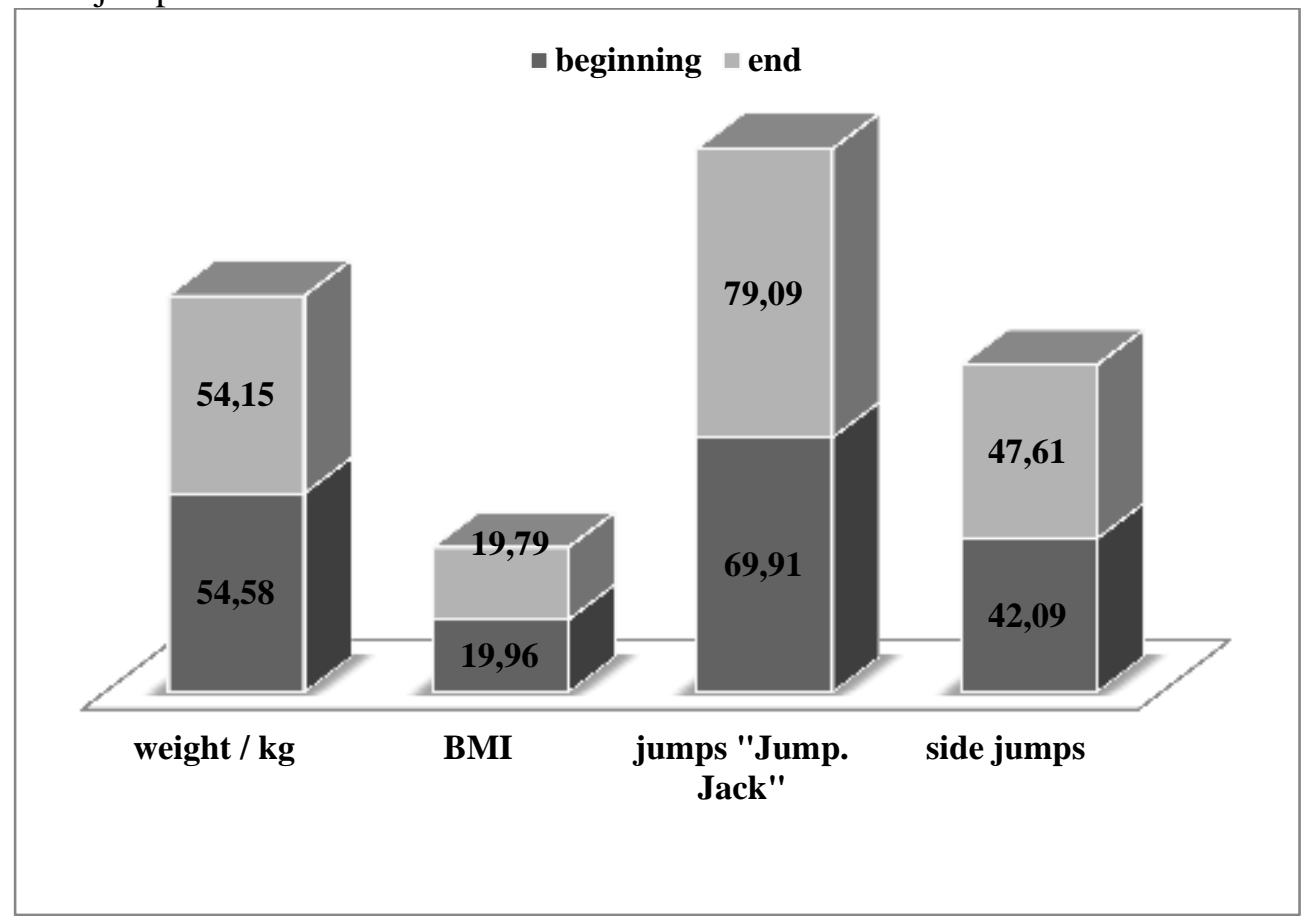

Figure 1. Average values of control indices in the beginning and in the end of the experiment carried out

In the end of the experiment carried out, no significant changes have been observed regarding the growth of the result in the exercises controlling the jump endurance of female students. At the vertical jumps we report increase by 10 , of the average achievement, and with the side ones, which in their character are a combination between horizontal and vertical jumps, the improvement is almost by 5 jumps. Independently of the average values on these indices, the comparative analysis between the poorest and the highest result in the group shows a satisfactory growth, which is adequate, in view of the investigated group of female students (Figure 2).

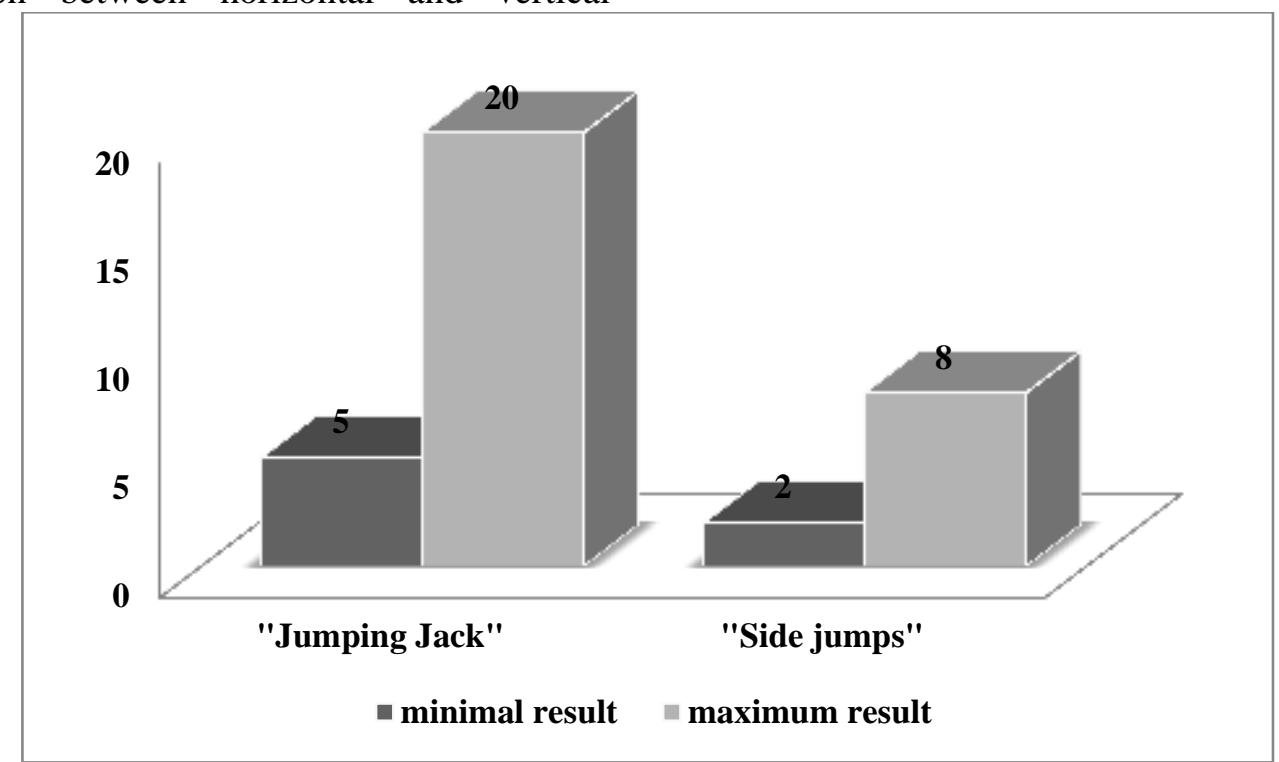

Figure 2. Growth of the result in the tests for jump endurance 
Measuring the pulse frequency prior and after physical loading gives us a possibility to follow up the recovery processes of cardiovascular system and to make general conclusions indirectly, regarding the general functional preparation of female students, from the UNWE, investigated by us (Figure 3).

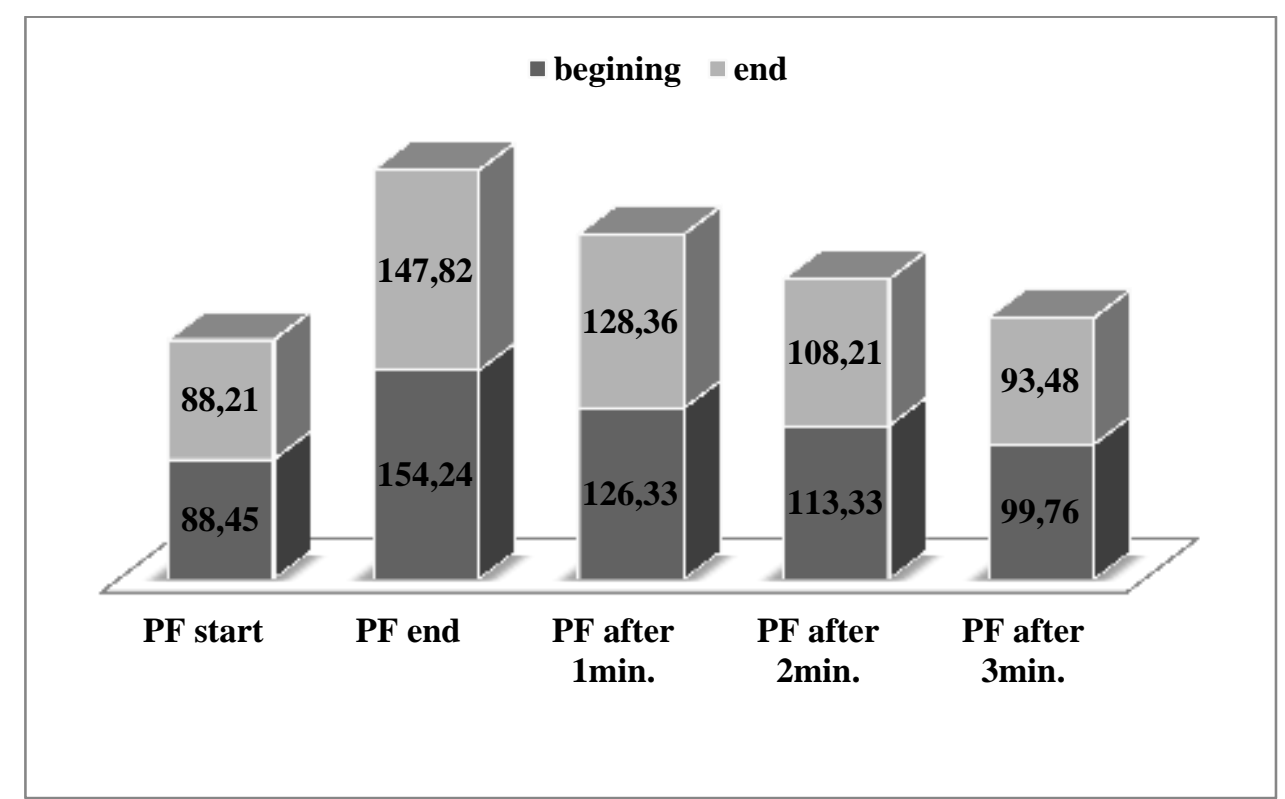

Figure 3. Values of pulse frequency in the beginning and in the end of the experiment

The investigated parameters of pulse frequency prior and after, and up to the $3^{\text {rd }}$ minute after the physical loading, define a highly heterogeneous group. The coefficient of variation is between $147,69 \%$ (reported on the $3^{\text {rd }}$ minute after the loading) and $356,25 \%$ (measured immediately after the loading).

There are some alarming values for pulse frequency prior starting the exercises that in single cases are 100-112 beats per minute. Irrespectively of the follow up of the recovery processes, where the regular dependency to decreasing the measured heart beats per minute is observed, we report a very low level of general functional preparation. It is too disturbing and gives an indication for lack of enough motor activity with the investigated by us female students of the age 19-22 years.

\section{CONCLUSIONS}

From the results got, we could summarize that the investigated group is homogeneous as regards the anthropometric tests and highly heterogeneous for the control jump exercises. Regardless of the fact that a regular dependency to decreasing of the measured heart beats per minute is observed, we report a very low level of general functional preparation. It is too disturbing and gives indication for lack of enough motor activity with the investigated by us female students of the age 19-22 years. In the end of the experiment, we report growth with the jump exercises, as well as a visible improvement of the adaptability to intensive exercises at Physical education and sports classes, in the UNWE. The survey carried out proved to be successful and the aim set by us for improving the jump endurance has been achieved, but in spite of this, it is necessary to look for new approaches for bigger effectiveness with the realization of the educational curriculums set.

\section{REFERENCES}

1. Ivanov, Iv., Physical education at Higher schools. Theory and Methods. S., Publ. UASG UIC, 1996.

2. Milanova, St., Shot put. Education and training, NSA PRESS. S. p.39, 2007.

3. Bachvarov, M., Thematic vocabulary on Sportology. Second edition. S. 2005.

2. Milanova, St., Experimenting of methods for development of explosive force with women- shot putters./in co-authorship/. Athletics and Science. p.1 (12), 2012

3. Kasabova, L., Possibilities for improving the speed power qualities of the female basketball players, Trakia Journal of Sciences, Vol.17, The Official Scientific Journal of Trakia University, Stara Zagora, Bulgaria, ISSN 1313-7069 (publ.), ISSN 1313-3551 (online) doi: 10.15547 / tjs.2019.s.01.125

4. Stavrev, S., Methods for complex assessment of psychophysical characteristics of students from economic 
IGNATOVA M., et al.

and managing sciences. Monograph, S., Publishing complex of UNWE, p. 140, 2016.

5. Arsova, R., Monograph - Force preparation of young volleyball players. PH-UNWE, ISBN 978-619-232-202-1, S., 2019.

6. Arsova, R., Assessment of training programmes for development of speed force qualities with volleyball players". International Journal Knowledge, Skopje,
2020, Scientific papers, Vol. 38. 6., pp. 1531 - 1535, ISSN 2545-4439.

7. Arsova, R., Efficiency of an experimental program for young volleyball players under field conditions. International Conference The Future of Education, 8th Conference edition, Florence, Italy, Libreriauniversitaria.it, 2018, pp. 424, ISBN: 978-88-3359-020-2; ISSN:23849509. 